\title{
Line balancing using heuristic procedure and simulation of assembly line
}

\author{
Mohammad Huskhazrin Kharuddin, Mohammad Fadzli Ramli, Muhamad Hafiz Masran \\ Institute of Mathematics Engineering, University Malaysia Perlis, Malaysia
}

\begin{tabular}{l} 
Article Info \\
\hline Article history: \\
Received Jan 10, 2019 \\
Revised May 1, 2019 \\
Accepted Jul 1, 2019 \\
\hline
\end{tabular}

Keywords:

Assembly line

Line balancing

Heuristics procedure

Simulation

\begin{abstract}
The assembly line is widely known because the use of it in manufacturing to process raw material into a complete product. There are many discussions and researches have been done in this field and the assembly line balancing problem is one of the topics that attract the interest of many researchers. The technique that frequently uses to solve assembly line balancing is a heuristic procedure. In this paper, a case study about the production of the power converter is studied. The assembly line of the power converter consists of 27 major tasks and 19 workstations. The existing heuristics procedures and a proposed heuristic procedure are used to solve the line balancing problem. After that, simulation is used to obtain the results and by comparing the results for each procedure, the most suitable procedure that should be used to solve the problem is selected.
\end{abstract}

Copyright () 2020 Institute of Advanced Engineering and Science. All rights reserved.

\section{Corresponding Author:}

Mohammad Huskhazrin Kharuddin, Institute of Mathematics Engineering, University Malaysia Perlis, Pauh Putra Main Campus, Perlis, Malaysia. Email: khazrinhus@yahoo.com

\section{INTRODUCTION}

This paper is the extended paper of Heuristic Method for Assembly Line Balancing and Simulation of Power Converter Assembly Line which published in IEEE 5th International Conference on Smart Instrumentation, Measurement and Applications (ICSIMA 2018). The assembly line balancing problem is studied. The heuristic methods are used to solve the problem and the simulations of power converter assembly line have been done to see the improvement [1]. Assembly line, Line balancing, Heuristics procedure, Simulation.

In the manufacturing system, there are more than one workstations which are linked together to form an assembly line and a set of tasks is assigned to each workstation in their respective order or precedence flow. It is called the assembly line and is used to process the raw material into a complete product. However, in order to create a finished product, the process of it must strictly follow the precedence flow and each workstation does their tasks [2, 3].

The optimization of the assembly line throughout the manufacturing process is emphasized based on two major activities. The first activity is to determine and to apply the most suitable automation level in the assembly line with the purpose of balancing the investment in automation and output. The assembly line balancing (ALB) is the second activity to optimize the assembly line by allocating the tasks into workstations and processing time needed for each workstation to complete their job is equal or almost equal [4, 5].

The way in which a set of task is assigned into workstation by sticking strictly to the precedence flow until all workstations have been more or less same processing time to finish their tasks is called ALB. The objective of ALB is to reduce the idle time of the assembly line and at the same time, able to increase the 
effectiveness of the assembly line by decreasing the number of workstations, or decreasing the cycle time, or both [6-8].

There are numerous numbers of industrial problems where the assembly line balancing problem (ALBP) is one of them [9]. It is said to be a complicated problem due to consideration of two significant points which are performances and costs. Generally, the performance of the assembly line is related to its product number per unit time that can be completed, also known as a throughput. Then, the cost is about overall resources (workers and equipment) required to complete all the tasks. Hence, performances and costs play a big role in the production. Fundamentally, trade-off problem between these two is the ALBP [10].

A few requirements are needed for a set of tasks to be assigned to workstations throughout the line balancing. The requirements are as followed, 1) a task that have been assigned to a workstation cannot be assigned to another workstation; 2) total time for each workstation to finish all their tasks must less or equal to cycle time; and 3) the precedence relationship must be followed rigidly by all tasks and cannot be disregard $[11,12]$.

Nowadays in the modern era where manufacture is well known, there are many researches available in literature. Their aims by doing these researches are nothing but to explain and uncover the mystery of ALB. Some of them are using the computer simulation software to build the simulation model that can be used to run the experimentation on the real system and then be able to find the best way to improve the system. Driscoll and Abdel-Shafi [13] using the combinations of line balancing and simulation approach to solve the ALBP for a mixed product assembly line. The heuristic method was used to balance the assembly line under certain balance confidence. Next, four layouts simulation were executed to analyse the layouts performance. By using idle time, lost time and some other parameter, performance between layouts were compared and the best layout was selected. McMullen and Frazier [14] studied seven line balancing problems and 23 heuristic methods are used to find the solution. Then, they run the simulation for these assembly lines and the results of simulation are used to determine which heuristic should be the most appropriate method for their problem. Mendes, Ramos, Simaria, and Vilarinho [15] has deriving the line configurations for a mixedmodel assembly line by using the metaheuristic method. The results obtained from meta-heuristic are used in simulation models. Performance measures such as processing time and utilization are used to see the improvement. The results would able to help the operational support to make a necessary arrangement to improve the assembly line.

Real-time and the dynamic balancing have been studied by Wang, Wang and Zhang [16] and they control these parameters by using the visual simulation model. A technique based on the genetic algorithm in a gear-box production system is proposed by them to solve the assembly line balancing problem. Kitaw, Matebu and Tadesse [17] have established a discrete-event simulation model of polo shirt production line. Simulation software is used as to develop different ways for the improvement of worker utilization. An algorithm based on simulation and genetic algorithm has been proposed by Fan, Gao, Xu and Xiao [18]. They investigated the modelling and simulation of the assembly line where overlapped and stopped operation is consisted. The objective function is determined via stochastic simulation and genetic algorithm where the optimal choice is selected.

Ruan, Tao, Peng and Chen [19] used soft computing approach to deal with the ALBP in the mobile phone production. The simulation model of real system was simulated to identify the unbalance in the assembly line. The assembly line performance before and after line balancing was compared using simulation method. Kurşun Bahadır [20] studied line balancing in the assembly line of garment. Simulation software is used to simulate the existing system and four scenarios were generated by applying what-if analyse by doing some adjustment and moving the workstation. The aims are to balance the assembly line and improve its efficiency. Hafezalkotob, Ketabian and Rahimi [21] presented the simulation approach for pipe assembly line with two different types of pipe. They used Enterprise Dynamics software to run the simulation and create new scenarios with end goal in their mind to improve the performance of assembly line.

The stochastic assembly line have been studied by Fazlollahtabar, Hajmohammadi and Es'Haghzadeh [22]. They proposed the new model based on the Rank Positional Weight algorithm and developed normal distribution integration and Monte Carlo simulation methodologies. Numerical analysis is used to compare the results and see the effectiveness of new proposed model. Kayar and Akalin [23] used the heuristic method which is Hoffman method and Arena simulation software to balance the blouse production line. They want to create the best assembly line and determine the applicability of Hoffman method to production line.

The combination of heuristic method and simulation approach to solve ALBP in power converter production is focused on this study. The details about existing assembly line will be described i.e. the time study and its precedence flow. Next, the existing assembly line simulation model was created and will be analyzed using simulation software. Then, two existing heuristic procedures and a proposed heuristic procedure will be used to apply line balancing on the assembly line. New simulation model will be formed 
based on line balancing results from these methods. After that, the new production lines and the actual line will be compared using simulation runs again. The result and improvement of assembly line will be discussed based on efficiency, balance delay, utilization and throughput.

\section{THE ASSEMBLY LINE OF POWER CONVERTER MODEL}

There are 27 tasks and 19 workstations in the assembly line of power converter model. An annual average operating time is 52 weeks with the work starts at 7.00 a.m and end at 5.00 p.m from Monday to Friday. The lunch break is at 12.00 p.m for one hour. The Figure 1 and Figure 2 will shows the location of workstations for the real power converter assembly line and it precedence flow respectively.

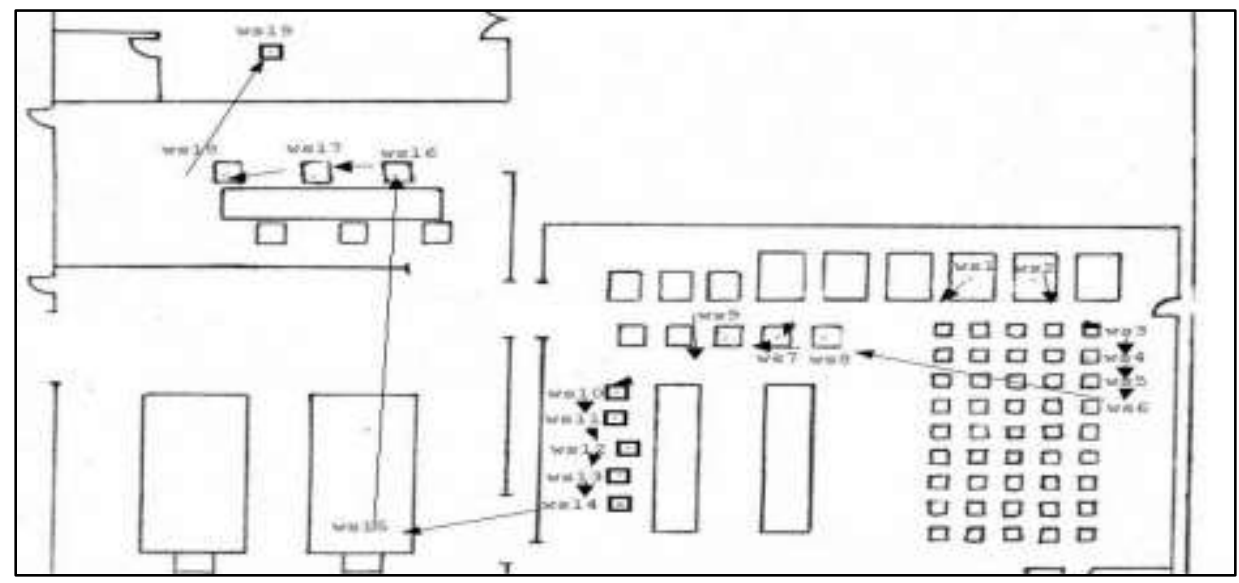

Figure 1. Actual assembly line

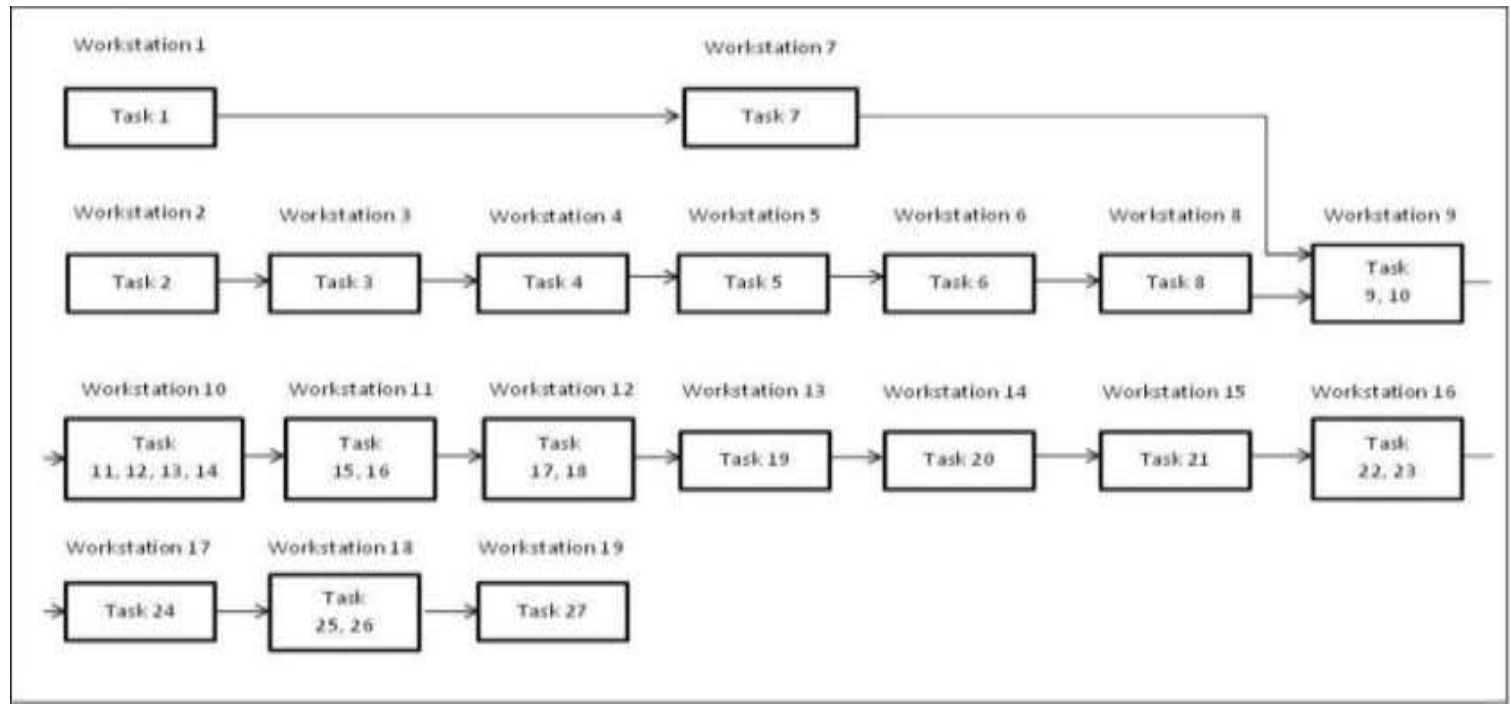

Figure 2. The precedence flow of assembly line

The assembly line able to produce an average 1000 units throughput in a day. Then, the cycle time with $90 \%$ efficiency can be calculated as follow:

$$
c=\frac{60 \times 9 \times 0.9}{1000}=0.4860 \text { minute }
$$

Before the simulation model can be simulated, all the input data must be identify and collected. The main input of the power converter assembly line simulation model is processing times of task. Hence, each 
task processing times was collected and then the most suitable probability distribution for the measured data is chosen. Lastly, the simulation model of actual line was runs 100 times for a day period according to inputs data by using ProModel software. After the simulation process, the throughput that the actual assembly line model could produce in a day is 845 units. The utilization of workstations in actual line obtained from simulation result is shown by Figure 3.

By assuming that the raw material is always available to process, from Figure 3, it easy to see that there are some unbalance among workstation utilization. The workstations that have highest utilization are workstation 3 and 10 while the others workstations are having low utilization. This means that the system is not in optimal condition because some of workstation runs at almost full capacity while others are mostly idle. In order to solve this problem, two different heuristic procedures and a proposed procedure, which are explained in Section 3, are used to balance the assembly line. The processing time for each task is given by Table 1.

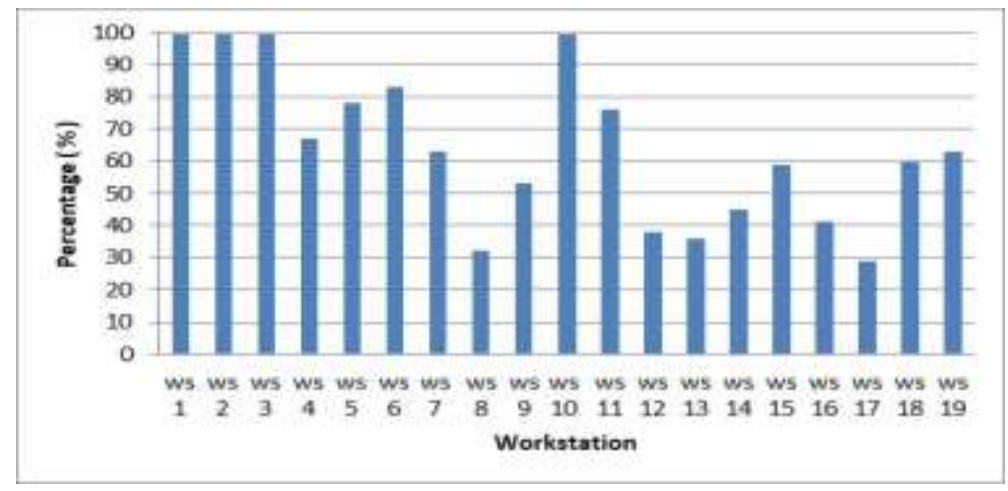

Figure 3. Workstations utilization of actual line

Table 1. The Processing Time for Tasks

\begin{tabular}{cc}
\hline Task (Work Element) & Processing Time $(\mathrm{min})$ \\
\hline 1 & 0.2992 \\
3 & 0.3088 \\
4 & 0.4453 \\
5 & 0.3020 \\
6 & 0.3485 \\
7 & 0.3710 \\
8 & 0.1880 \\
9 & 0.1440 \\
10 & 0.0917 \\
11 & 0.1425 \\
12 & 0.3008 \\
13 & 0.1373 \\
14 & 0.0400 \\
15 & 0.1545 \\
16 & 0.3305 \\
17 & 0.1547 \\
18 & 0.1758 \\
19 & 0.0632 \\
20 & 0.2285 \\
21 & 0.2898 \\
22 & 0.3750 \\
23 & 0.1837 \\
24 & 0.0802 \\
25 & 0.1808 \\
26 & 0.3560 \\
27 & 0.0277 \\
& 0.4018 \\
\hline
\end{tabular}

\section{HEURISTIC PROCEDURES FOR ASSEMBLY LINE BALANCING AND ITS SIMULATION}

The heuristic method is defined as a technique problem solving in which the approach is intuitionally to obtain rational solution and it can be apply in solving line balancing. Base on processing time and precedence constraints, tasks are assigned into workstations. Uncomplicated problem can be evaluated 
by all probable sets of tasks. On the other hand, trying different configuration is better to be stopped if more complex problems are involved. The line performance can be measured by using the formula for line efficiency or called utilization. The efficiency (E) can be calculated as follow:

$$
E=\frac{\sum_{i=1}^{j} p_{t i}}{w_{n} \times c_{t}}
$$

where $p_{t i}$ is the processing time for task, $i, j$ is the number of tasks, $w_{n}$ is the number of workstations and $c_{t}$ is cycle time. In addition, balance delay or called total idle time of line can be calculated as follow: (1 efficiency) [24]. Three heuristic procedures, largest candidate rule, ranked positional weight method and proposed procedure are used in this study to balance the assembly line. Then, for each approach, the line efficiency and total idle time of line are calculated.

\subsection{Largest Candidate Rule (LCR)}

This heuristic method is the most simple and easy to understand. It's one of the earlier methods which have been proposed to solve ALBP. The size of their processing time will be the basis for assigning the task into workstation. In this method, processing time of task is arranged in descending order where the task with largest processing time at the top of the list whereas the task with smallest processing time at the bottom. The allocation of tasks into workstation base on LCR is given by Table 2. The number of workstations after line balancing is reduced to 16 and the efficiency or utilization of assembly line is increased to $79 \%$. Therefore, the idle time of the assembly line balanced by LCR is computed as $21 \%$.

Table 2. Allocation of Tasks Base on LCR

\begin{tabular}{|c|c|c|c|}
\hline Workstation & $\begin{array}{c}\text { Task } \\
\text { (Work Element) }\end{array}$ & $\begin{array}{l}\text { Processing time } \\
(\min )\end{array}$ & $\begin{array}{l}\text { Total Time in Workstation } \\
\text { (min) }\end{array}$ \\
\hline 1 & 2 & 0.3088 & 0.3088 \\
\hline 2 & 3 & 0.4453 & 0.4453 \\
\hline 3 & 4 & 0.3020 & 0.3020 \\
\hline 4 & 5 & 0.3485 & 0.3485 \\
\hline 5 & 6 & 0.3710 & 0.3710 \\
\hline \multirow[t]{2}{*}{6} & 1 & 0.2992 & 0.4432 \\
\hline & 8 & 0.1440 & \\
\hline \multirow[t]{3}{*}{7} & 7 & 0.1880 & 0.4222 \\
\hline & 9 & 0.0917 & \\
\hline & 10 & 0.1425 & \\
\hline \multirow[t]{3}{*}{8} & 11 & 0.3008 & 0.4782 \\
\hline & 12 & 0.1373 & \\
\hline & 13 & 0.0400 & \\
\hline \multirow[t]{2}{*}{9} & 14 & 0.1545 & 0.4850 \\
\hline & 15 & 0.3305 & \\
\hline \multirow[t]{3}{*}{10} & 16 & 0.1547 & 0.3937 \\
\hline & 17 & 0.1758 & \\
\hline & 18 & 0.0632 & \\
\hline 11 & 19 & 0.2285 & 0.2285 \\
\hline 12 & 20 & 0.2898 & 0.2898 \\
\hline 13 & 21 & 0.3750 & 0.3750 \\
\hline \multirow[t]{3}{*}{14} & 22 & 0.1837 & 0.4447 \\
\hline & 23 & 0.0802 & \\
\hline & 24 & 0.1808 & \\
\hline \multirow[t]{2}{*}{15} & 25 & 0.3560 & 0.3837 \\
\hline & 26 & 0.0277 & \\
\hline 16 & 27 & 0.4018 & 0.4018 \\
\hline
\end{tabular}

$$
E=\frac{\sum_{i=1}^{j} p_{t i}}{w_{n} \times c_{t}}=\frac{6.1213}{16 \times 0.4860}=0.7872 \approx 79 \%
$$

\subsection{Ranked Positional Weight Method (RPW)}

RPW method was developed by Helgeson and Birnie [25]. It is one of heuristic that can be used to solve assembly line balancing problem. When line balancing is applied to assembly line using this method, 
the allotment of tasks into workstation simply on the basis of the value of positional weight and each task has their positional weight. It is calculated by adding the processing times of the task itself and all the tasks that directly follow it in the precedence diagram. The tasks are allocated to workstation in decreasing order of their positional weight.

This RPW method show that the relationship between the numbers of task that are available for allotment and the probability that at least one task will fit at a particular workstation is directly proportional. Hence, it is not difficult to find suitable task and use the most of each station's cycle time. Then, this should result in reduce the number of workstation and idle time [26, 27]. By using RPW method to solve the assembly line balancing problem, the result was same as the result when using the method of LCR. Therefore, line efficiency and idle time of line balanced by RPW method is $79 \%$ and $21 \%$ respectively.

\subsection{The Proposed Heuristic Procedure}

A good queuing system is a system that has small value of waiting time or idle time [28]. The proposed heuristic procedure is based on concept of queuing system where there are input as a customer and workstation as a serve. Arrival time of input and processing time of task will be used in order to assign the tasks into workstation. The procedure is as follow:

a. Tasks are assigned to a workstation, one at a time following the tasks precedence and allocate the task start with the most numbers of subsequent tasks.

b. Chosen task should be based on the arrival time of input and processing time of task. Tasks are added into workstation if arrival time of input is more than processing time.

c. If possible, add the task into workstation until total processing time equal to arrival time of input.

d. However, if total processing times exceed arrival time, the total processing time should close to cycle time, the different must not exceed $10 \%$.

e. In case there are two or more allocable tasks at the same time, choose the task that will have the closest total processing time to cycle time.

f. The procedure 2-5 is repeated on the next workstation for the remaining tasks.

Table 3 shows the assignment of task base on proposed heuristic. The number of workstation after using proposed procedure is reduced to 15 and the efficiency of assembly line is $84 \%$. The total idle time of the line balanced by proposed procedure is computed as $16 \%$.

$$
E=\frac{\sum_{i=1}^{j} p_{t i}}{w_{n} \times c_{t}}=\frac{6.1213}{15 \times 0.4860}=0.8397 \approx 84 \%
$$

Table 3. Assignment of Tasks Base on Proposed Heuristic

\begin{tabular}{|c|c|c|c|}
\hline Workstation & $\begin{array}{c}\text { Task } \\
\text { (Work Element) }\end{array}$ & $\begin{array}{l}\text { Processing time } \\
\text { (min) }\end{array}$ & $\begin{array}{c}\text { Total Time in } \\
\text { Workstation (min) }\end{array}$ \\
\hline 1 & 2 & 0.3088 & 0.3088 \\
\hline 2 & 3 & 0.4453 & 0.4453 \\
\hline 3 & 4 & 0.3020 & 0.3020 \\
\hline 4 & 5 & 0.3485 & 0.3485 \\
\hline 5 & 6 & 0.3710 & 0.3710 \\
\hline \multirow[t]{2}{*}{6} & 1 & 0.2992 & 0.4432 \\
\hline & 8 & 0.1440 & \\
\hline \multirow[t]{3}{*}{7} & 7 & 0.1880 & 0.4222 \\
\hline & 9 & 0.0917 & \\
\hline & 10 & 0.1425 & \\
\hline \multirow[b]{2}{*}{8} & 11 & 0.3008 & 0.4381 \\
\hline & 12 & 0.1373 & \\
\hline \multirow[t]{3}{*}{9} & 13 & 0.0400 & 0.5250 \\
\hline & 14 & 0.1545 & \\
\hline & 15 & 0.3305 & \\
\hline \multirow[t]{3}{*}{10} & 16 & 0.1547 & 0.3937 \\
\hline & 17 & 0.1758 & \\
\hline & 18 & 0.0632 & \\
\hline \multirow[t]{2}{*}{11} & 19 & 0.2285 & 0.5183 \\
\hline & 20 & 0.2898 & \\
\hline 12 & 21 & 0.3750 & 0.3750 \\
\hline \multirow[t]{3}{*}{13} & 22 & 0.1837 & 0.4447 \\
\hline & 23 & 0.0802 & \\
\hline & 24 & 0.1808 & \\
\hline \multirow[t]{2}{*}{14} & 25 & 0.3560 & 0.3837 \\
\hline & 26 & 0.0277 & \\
\hline 15 & 27 & 0.4018 & 0.4018 \\
\hline
\end{tabular}




\subsection{Simulation of Power Converter Assembly Line using ProModel}

After line balancing of power converter assembly line has been completed by using LCR, RPW and proposed methods, three simulation models are created base on these results. The new lines were set to run for a day period by using ProModel 2011. Then, the daily average throughput and utilization of workstation were used as performance measure. Table 4 shows the daily average output of four lines.

Table 4. The Daily Average Output

\begin{tabular}{cc}
\hline Assembly Line & Daily Output \\
\hline Real Line & 845 \\
Line balanced by Largest Candidate Rule & 977 \\
Line balanced by Ranked Positional Weight Method & 977 \\
Line balanced by Proposed Heuristic Procedure & 1017 \\
\hline
\end{tabular}

As it can be seen from Table 4, biggest number of throughput was obtained from the line balanced by proposed procedure. As for output obtained from procedure I and II, the amount is more than amount obtained from real line. The utilization of workstations for new lines after using procedure I and II is shown in Figure 4 and Figure 5 show the workstation utilization after balancing using proposed heuristic procedure. Based on the results obtained after simulate the line with 16 workstations (procedure I and II), the rate of utilization of the workstations has improved and much more balanced compare to existing line. However, by using proposed procedure, the workstation utilization is much better and more balanced.

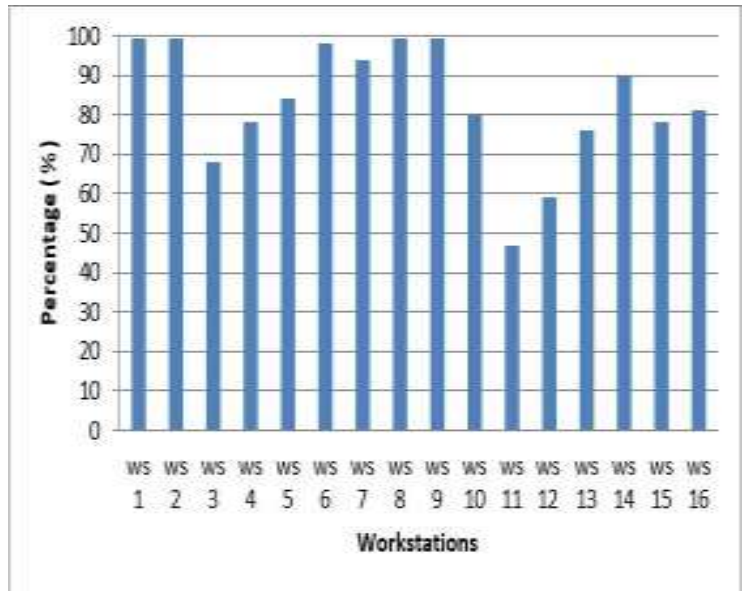

Figure 4. Utilization of workstation after balancing using heuristic procedure I and II

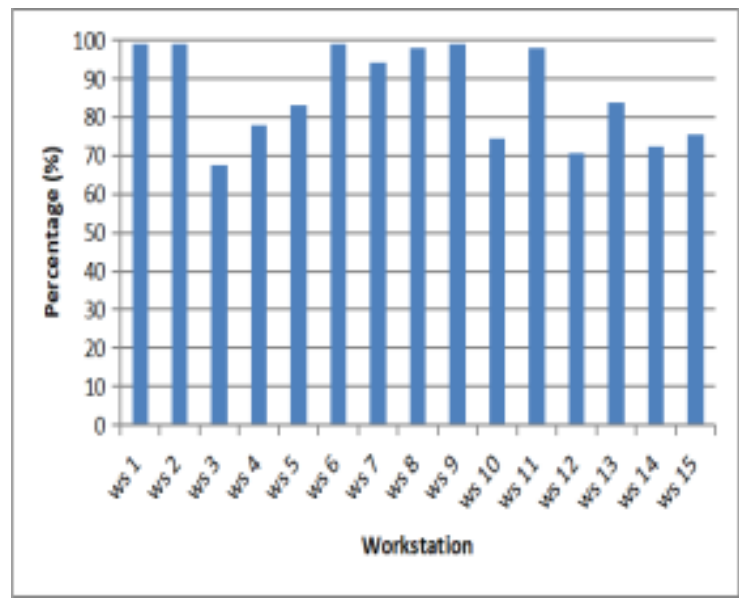

Figure 5. Utilization of workstation after balancing using proposed heuristic

\section{CONCLUSION}

In this paper, assembly line balancing problem is analysed and the case study of power converter assembly line is presented. The actual line is studied and two heuristic procedures (LCR and RPW) and a proposed procedure are used to solve the assembly line balancing problem. The simulation model of the real line and the new lines are created based on those results and in order to see the improvements, simulations of each line are performed. The throughput and utilization are used as performance measures to help in making the best decision. Both the assembly line in procedure I and II have 16 workstations. Nevertheless, only 15 workstations consist in assembly line of proposed procedure. The daily average output produce by real line is the smallest output because it is unbalanced. The daily average output produce by line balanced with procedure I and II is 977 units and line balanced with proposed procedure is produced 1017 units output. Therefore, the proposed procedure is the best choice. For future research, proposed another heuristic method or using other method to solve assembly line balancing problem and their simulation can be proposed. 


\section{ACKNOWLEDGEMENTS}

The authors would like to acknowledge the support from Universiti Malaysia Perlis (UniMAP) and the Fundamental Research Grant Scheme (FRGS) under a grant number of FRGS/1/2016/STG06/UNIMAP/03/6 from the Ministry of Higher Education Malaysia.

\section{REFERENCES}

[1] M.H. Kharuddin, M.F. Ramli and M.Z. Zakaria, "Heuristic Method for Line Balancing and Simulation of Power Converter Assembly Line," IEEE 5rd International Conference on Smart Instrumentation, Measurement and Applications, 2018.

[2] N. Boysen, M. Fliedner and A. Scholl, "Assembly Line Balancing: Which Model to Use When?," International Journal of Production Economics, vol. 111, no. 2, pp. 509-528, 2008.

[3] T. Kellegöz, "Assembly Line Balancing Problems With Multi-Manned Stations: A New Mathematical Formulation and Gantt Based Heuristic Method," Annals of Operations Research, vol. 253, no. 1, pp. 377-404, 2017.

[4] M.F.F. Rashid, W. Hutabarat and A. Tiwari, "A Review on Assembly Sequence Planning and Assembly Line Balancing Optimization using Soft Computing Opproaches," International Journal of Advanced Manufacturing Technology, vol. 59, no. 1-4, pp. 335-349, 2011.

[5] Z. Li, I. Kucukkoc and J.M. Nilakantan, "Comprehensive Review and Evaluation of Heuristics and Meta-Heuristics for Two-Sided Assembly Line Balancing Problem," Computers \& Operations Research, vol. 84, pp. 146-161, 2017.

[6] B. Das, J.M. Sanchez-Rivas, A. Garcia-Diaz and C.A. MacDonald, "A Computer Simulation Approach to Evaluating Assembly Line Balancing with Variable Operation Times," Journal of Manufacturing Technology Management, vol. 21, no. 7, pp. 872-887, 2010.

[7] Z. Yuguang, A. Bo and Z. Yong, "A PSO Algorithm for Multi-Objective Hull Assembly Line Balancing using the Stratified Optimization Strategy," Computers \& Industrial Engineering, vol. 98, pp. 53-62, 2016.

[8] M.R.A Make, M.F.F.A. Rashid and M.M. Razali, "A Review of Two-Sided Assembly Line Balancing Problem," The International Journal of Advanced Manufacturing Technology, vol. 89, no. 5-8 , pp. 1743-1763, 2017.

[9] R. Pitakaso and K. Sethanan, "Modified Differential Evolution Algorithm for Simple Assembly Line Balancing with a Limit on The Number of Machine Types," Engineering Optimization, vol. 48, no. 2, pp. 253-271, 2016.

[10] L. Tiacci, "Coupling a Genetic Algorithm Approach and a Discrete Event Simulator to Design Mixed-Model Unpaced Assembly Lines with Parallel Workstations and Stochastic Task Times," International Journal of Production Economic, vol. 159, pp. 319-333, 2015.

[11] P. Chutima and H. Suphapruksapongse, "Practical Assembly Line Balancing in a Monitor Manufacturing Company," Thammasat International Journal of Science and Technology, vol. 9, no. 2, pp. 62-70, 2004.

[12] Y.G. Zhong and B. Ai, "A Modified Ant Colony Optimization Algorithm for Multi-Objective Assembly Line Balancing," Soft Computing, vol. 21, no. 22, pp. 6881-6894, 2017.

[13] J. Driscolla and A.A. Abdel-Shafi, "A Simulation Approach to Evaluating Assembly Line Balancing Solutions," International Journal of Production Research, vol. 23, no. 5, pp. 975-985, 1985.

[14] P.R. McMullen and G.V. Frazier, "Using Simulation and Data Envelopment Analysis to Compare Assembly Line Balancing Solutions," Journal of Productivity Analysis, vol. 11, no. 2, pp. 149-168, 1999.

[15] A.R. Mendes, A.L. Ramos, A.S. Simaria and P.M. Vilarinho, "Combining Heuristic Procedures and Simulation Models for Balancing a PC Camera Assembly Line," Computers and Industrial Engineering, vol. 49, no. 3, pp. 413-431, 2005

[16] H. Wang, H. Wang and H. Zhang, "Study of Assembly Line Dynamic Balancing Based on Simulation," International Technology and Innovation Conference (ITIC), pp 1-4, 2009.

[17] D. Kitaw, A. Matebu, S, Tadesse, "Assembly Line Balancing Using Simulation Technique In A Garment Manufacturing Firm," Journal of EEA, vol. 27, pp. 69-80, 2010

[18] W. Fan, Z. Gao, W. Xu and T. Xiao, "Balancing and Simulating of Assembly Line with Overlapped and Stopped Operation," Simulation Modelling Practice and Theory, vol. 18, no. 8, pp. 1069-1079, 2010.

[19] L.Z. Ruan, W.D. Tao, J.L. Peng and Y. Chen, "Assembly Line Balancing and Simulation Optimization of the TM921C Mobile Phone Assembly Line of DFTX Company," IEEE 18Th International Conference on Industrial Engineering and Engineering Management (IE\&EM), pp. 687-692, 2011.

[20] S. Kurşun Bahadır, "Assembly Line Balancing in Garment Production by Simulation. Assembly Line - Theory and Practice," by Prof. Waldemar Grzechca (Ed.), InTech, 2011.

[21] A. Hafezalkotob, H. Ketabian and H. Rahimi, "Balancing the Production Line by the Simulation and Statistics Techniques: A Case Study, "Journal of Applied Sciences, Engineering and Technology, vol. 7, no. 4, pp. 754-763, 2014.

[22] H. Fazlollahtabar, H. Hajmohammadi and A. Es'Haghzadeh, "A Heuristic Methodology for Assembly Line Balancing Considering Stochastic Time and Validity Testing," The International Journal of Advanced Manufacturing Technology, vol. 52, pp. 311-320, 2011.

[23] M. Kayar and M. Akalin, "Comparing Heuristic and Simulation Methods Applied to the Apparel Assembly Line Balancing Problem," Fibres and Textiles in Eastern Europe, vol. 24, no. 2(116), pp. 131-138, 2016

[24] R.S. Russell and B.W. Taylor, "Operations Management: Creating Value Along the Supply Chain," 7th Ed. USA. 2011. 
[25] W.B. Helgeson and D.P. Birnie, "Assembly Line Balancing using the Ranked Positional Weight Technique. Journal of Industrial Engineering, vol. 12, no. 6, pp. 394-398, 1961.

[26] D.J. Fonseca, C.L. Guest, M. Elam and C.L. Karr, "A Fuzzy Logic Approach to Assembly Line Balancing," Mathware \& Soft Computing, vol. 12, no. 1, pp. 57-74, 2005.

[27] N. Ismail, I. Nursalim, H.M. Saputra, and T.S. Gunawan, "Implementation of fuzzy logic control system on rotary car parking system prototype," Indonesian Journal of Electrical Engineering and Computer Science, 12 (2). pp. 706-715, 2018.

[28] S. Khalili, H. Mohammadzade and M.S. Fallahnezhad, "A New Approach Based on Queuing Theory for Solving the Assembly Line Balancing Problem using Fuzzy Prioritization Techniques," Scientia Iranica, vol. 23, no. 1, pp. 387-398, 2016. 